\title{
The Influence of Emotional Support from Parents, Peers, and Romantic Partners on Changes in Purpose in Life and Mastery in Young Adulthood
}

\author{
Paweena Sukhawathanakul, Megan E. Ames and Bonnie J. Leadbeater
}

\begin{abstract}
Purpose in life and mastery over one's environment are important assets for positive youth development but little is known about how they change or interact during the transition to young adulthood, or how they may be moderated by support from relationships. The current study examines longitudinal associations between purpose in life and mastery in a sample of Canadian youth $(N=662)$ ages 18 to 29 across three biennial waves of data. Purpose in life and mastery were reciprocally associated within and across time, suggesting that these assets develop in tandem. However, emotional support from friends and romantic partners also moderated the associations. Specifically, the reciprocal association were significant for youth with high levels of friend and romantic partner support, but not for youth with low levels of support. Father and mother emotional support did not moderate the pathways. Findings highlight the importance of peer and romantic partner emotional support in cultivating youth's sense of purpose in life and mastery during the transition to young adulthood.
\end{abstract}

Keywords: youth, purpose, mastery, emotional support, parent support, peer support, romantic partner support

\footnotetext{
Paweena Sukhawathanakul is a Post-doctoral Fellow with the Centre on Aging at the University of Manitoba. Research interests include factors that promote positive youth development, specifically, predictors of well-being, positive peer relationships, and factors that promote social responsibility in children and youth. Recent publication: Leadbeater, B. J., Thompson, K., \& Sukhawathanakul, P. (2016). Enhancing social responsibility and prosocial leadership to prevent aggression, peer victimization, and emotional problems in elementary school children. American Journal of Community Psychology, 1-12.
} 
Megan Ames is a Post-doctoral Fellow with the Department of Psychology at the University of Victoria. Her research interest focuses on adolescent health risk behaviours including predictors of cardiometabolic risk in young adulthood (e.g., psychosocial problems and health behaviours). Recent publication: Ames, M., \& Leadbeater, B. (2016). Overweight and isolated: The interpersonal problems of youth who are overweight from adolescence into young adulthood. International Journal of Behavioral Development, 41(3), 390-404. doi:10.1177/0165025416647799

Bonnie Leadbeater is a Professor with the Department of Psychology at the University of Victoria. Her research interests include mental health and behavioural problems in adolescents and young adults with a specific interest in adolescent parenting, emerging adulthood, adolescent depression, resilience in high-risk youth, and the prevention of peer victimization in elementary school children. Recent publication: Leadbeater, B., Thompson, K., Sukhawathanakul, P., \& Merrin, G. (2018). The longitudinal effects of implementation fidelity and generalization on program outcomes: Scaling up the WITS programs in rural Canadian elementary schools. Prevention Science. https://doi.org/10.1007/s11121-018-0948-8 


\section{Introduction}

An increasing interest in understanding positive youth development has motivated scholars to pursue research that examines what fosters well-being and purpose in life. Conceptualizations of positive youth development shift our attention from developmental deficits that are often related to contextual disadvantages to consider the interactions between personal motivation and agency with available contextual supports and opportunities. Youth are also seen as active agents and their development is embedded in but not determined by their social contexts (Lerner, 2017). While mastery and finding purpose in life are key components of development in the transition to young adulthood, research on the social supports that scaffold these characteristics is limited, particularly in the transition to young adulthood. Parents are often conceptualized as guardians who must also gradually monitor the impulsivity and risk taking that is fostered by the negative influences of peers and romantic partners, and also gradual withdrawal to afford the growth of autonomy (Brauer, 2017). From a positive development perspective, we hypothesize that emotional support from parent, peer and romantic partners supports the growth of mastery and purpose in life across young adulthood.

Purpose in life and mastery, or agency in managing one's environment, are conceptualized as important assets for development that can propel an individual along a healthy trajectory across the life course. Youth who possess these assets engage in more prosocial acts and avoid risky behaviours (Burrow \& Hill, 2011; Cotton Bronk et al., 2009; Lerner, Dowling, \& Anderson, 2003). In this study, purpose in life signifies having future goals, intentions, and a sense of direction; whereas mastery involves the experience of agency or control over one's environment that enables individuals to choose or create contexts appropriate for their personal needs and values (Ryff, 1989). Together, it is likely that dedication to a purpose also enables youth to feel more competent in achieving daily goals (Burrow, O’Dell, \& Hill, 2010).

Although identity formation has historically been considered a key developmental task of adolescence (Erikson, 1968), the prolonged transition to adulthood in post-industrial societies grants extended psychosocial moratoria where some youth are afforded opportunities to explore their identities well into their 20s (Arnett, 2000; Côté, 2009). Young adulthood offers further opportunities for youth to experiment with various identity roles when they enter post-secondary education, begin to live independently, develop long-term romantic relationships, rework relationships with parents and solidify meaningful friendships. However, little is known about the development of purpose and mastery in this critical age period or what contexts foster the interaction of these processes over time.

The current study addresses two important questions regarding the development of purpose in life and mastery in the transition to young adulthood: (1) How do purpose and mastery change over the transition to young adulthood and do they develop in parallel or influence one another over time? (2) What social contexts influence the relation between purpose in life and mastery? With a longitudinal sample of Canadian youth ages 18 to 29, we test the reciprocal relations between purpose in life and mastery over time and investigate whether emotional support from parents, friends, and romantic partners moderate these associations. We also examine whether the pathways between purpose in life and mastery differ for male and female participants. 


\section{Purpose in Life during Young Adulthood}

Achieving a sense of purpose in life has traditionally been considered a protective factor in the face of adversity (Frankl, 1959). It has also been conceptualize as an aspect of identity development (Erikson, 1968). We adopt Ryff's (1989) definition of purpose in life to denote an individual's sense of directedness and intentionality, both of which contribute to the feeling that life is meaningful. This is consistent with Damon, Menon, and Cotton Bronk's (2003) definition, which highlights purpose in life as an individual's personal search for meaning and motivations to accomplish far-reaching, higher-level goals than short-term goals.

Having a sense of purpose in life during adolescence, in particular, has been linked to a range of positive emotional and behavioural outcomes. For example, Malin, Liauw, and Damon (2017) found that a greater sense of purpose in life during adolescence was associated with positive character strengths (e.g., gratitude, compassion, and grit). Burrow and Hill (2011) found that purpose was directly associated with daily positive affect and inversely related to daily negative affect. Purpose in life is also associated with higher academic achievement (Pizzolato, Brown, \& Kanny, 2011). Adolescents who demonstrate a greater sense of meaning and purpose in life are also less likely to engage in health risk behaviours such as substance use (Minehan, Newcomb, \& Galaif, 2000), as well as unsafe sexual behaviours, lack of exercise, and diet control (Brassai, Piko, \& Stegger, 2011). Moreover, purpose in life can impact adolescent psychological adjustment. Youth who possess a greater sense of purpose in life report fewer mental health problems (internalizing and externalizing symptoms; Hardy et al., 2014) and suicidal ideations (Henry et al., 2014). Further longitudinal investigations are needed to determine if the benefits of having a purpose in life continue into young adulthood when youth are charged with making challenging decisions (e.g., entry to post-secondary, career pathways) that hold long-term implications for their future.

\section{Mastery in Young Adulthood}

Mastery is defined as the capacity to effectively manage one's life and surroundings is an important psychological resource that promotes well-being (Ryff \& Keyes, 1995) and a key aspect of positive youth development (Lerner et al., 2003). Facets of mastery can include competence in decision-making, agency, and efficacy in choosing contexts that are congruent with one's goals and needs (Ryff, 1989). Although several definitions of mastery exist (e.g., Emirbayer \& Mische, 1998; Kiecolt \& Mabry, 2000), for the present study, we use Ryff's (1989) definition of mastery as it encompasses both a sense of control over their context or environment and competence in decision-making.

Individuals with a sense of mastery are more agentic, as they display little difficulty managing everyday affairs, take advantage of environmental opportunities, and feel able to change or improve their surrounding context. This definition of mastery also shares similarities with Côté and Levine's (2002) definition of agency, which refers to an individual's sense of responsibility and control in their decisions, as well as the confidence in one's abilities to effectively navigate life's obstacles. Past research shows this definition of mastery is positively associated with identity 
achievement, exploration, deliberate decision making, and flexible commitment and negatively related to identity diffusion, avoidance, and aimlessness (Côté \& Schwartz, 2002; Schwartz et al., 2005). Individuals who are high in mastery are likely to have a strong sense of self that can guide explorations of a variety of possible life directions, whereas individuals low in mastery may be unprepared to explore the opportunities available to them (Ryff, 1989; Schwartz et al., 2005).

In general, longitudinal research suggests that individuals high in mastery (conceptualized as personal control, competence or self-efficacy) have higher socioeconomic status (e.g., more opportunities for occupational and educational attainment) and better mental health in adolescence and young adulthood (Adler, 2011; Colman et al., 2014; Hitlin, Erickson, \& Brown, 2015). For example, using a large national sample of Canadian adolescents, Colman and colleagues (2014) found mastery during adolescence was protective of depression in adulthood. Mastery has also been shown to predict high levels of positive affect and life satisfaction in a sample of Swedish adolescents (Garcia \& Siddiqui, 2009). Research has not investigated whether mastery changes during the transition to young adulthood as youth begin to be more autonomous and begin to navigate new adult roles and responsibilities.

\section{The Relation between Purpose in Life and Mastery}

The relationship between purpose in life and mastery in the transition to young adulthood is of particular interest. Researchers have theorized that purpose in life contributes to an agentic personality, which enables an individual to master their daily activities, overcome obstacles, and manage their environments (Schwartz et al., 2005). Identifying a purpose can also help youth formulate goals that provide meaning and a sense of mastery, thereby facilitating the transition to young adulthood. Both personal assets are components of optimal functioning and well-being (Ryff \& Keyes, 1995). During the transition to young adulthood, youth with a sense of purpose may be motivated to master opportunities that fit with their perceived strengths to maximize efforts to achieve their goals which, in turn, enhance self-efficacy and mastery. This suggests that the positive relations between purpose in life and mastery are reciprocal. The first objective of the present study is to empirically examine the direction of the association between purpose in life and mastery using three waves of data spanning six years for youth ages 18 to 25 at baseline. More specifically, we test whether purpose in life drives the development of mastery or vice versa, or whether they develop in tandem, influencing each other over time.

\section{The Effects of Emotional Support on the Development of Purpose in Life and Mastery}

Despite evidence that independently links purpose and mastery to positive outcomes, the contexts that support youth's development of purpose in life and mastery in young adulthood has received little attention. Hill, Burrow, and Sumner (2013) summarized the current state of the research field on youth's purpose and identified a "need to understand which contexts best scaffold the development of purpose among youth" (p. 232). Purpose in life includes an individual's intention to achieve something that is meaningful to both the self and to one's boarder community 
(Damon et al., 2003) and supportive social contexts maybe needed to reinforce youth's feeling of connection to their community. Moreover, meta-analytic reviews of interventions that promote positive youth development (e.g., Tolan, Ross, Arkin, Godine, \& Clark, 2016) calls for programs that support youth's development of mastery and competence by creating supportive contexts that align youth needs and skills with opportunities that enable them to be agents of their own thriving.

Research shows emotional support from family, peers, or romantic partners can help facilitate well-being in the transition to young adulthood (Adams \& Marshall, 1996; Côté \& Levine, 2014; Desjardins \& Leadbeater, 2017; Meeus, Oosterwegel, \& Vollebergh, 2002). Evidence suggests that high levels of social support can create greater sense of belonging that is central to having a purpose in life (e.g., Hagerty, Williams, \& Oe, 2002; Jose, Ryaa, \& Pryor, 2012; Lambert et al., 2013). Social contexts can also shape motivations to pursue goals as well as the determination to accomplish them (Deci \& Ryan, 2012). Messages about purpose and meaning can be conveyed to youth through interactions with parents, peers, and romantic partners. For example, research demonstrates that daily activities that include family obligations (e.g., helping parents or siblings with tasks) are positively associated with daily purpose, suggesting that family obligations may aid the development of purpose in life (Kiang, 2011; Kiang et al., 2013). Here, we hypothesize that youth with better social support systems will report greater purpose in life and higher levels of mastery. On the other hand, youth with low social support may be less likely to establish enduring connections between purpose in life and mastery over the transition to young adulthood.

Arnett (2000) argues that individuals continue to explore various identity roles in the transition to young adulthood, but also rely on important sources of support for the feedback and emotional encouragement needed to help focus and guide their commitments to a purpose in life. However, research on how social support contributes to purpose and mastery within this developmental period is lacking. We know very little about how purpose and mastery changes across the transition from adolescence to young adulthood and what sources of social support continue to influence their interaction and growth over time. The second objective of the present study is to examine whether emotional support from family, peers, and romantic partners moderate the longitudinal associations between purpose in life and mastery during the transition to young adulthood.

\section{The Current Study}

The current study aims to understand how purpose and mastery develop over the transition to young adulthood in a longitudinal sample of Canadian youth who participated in the final three waves of the Victoria Healthy Youth Survey (V-HYS; see Leadbeater, Thompson, \& Gruppuso, 2012 for details). We first use latent growth analysis to describe trajectories of purpose in life and mastery across the transition to young adulthood. Next, we assess the reciprocal associations between purpose in life and mastery. We then examine whether emotional sources of support from parents, friends, and romantic partners moderate the association between purpose in life and mastery. We hypothesize that purpose in life and mastery will be more strongly related over time for youth who report high levels of support from parents, peers, and romantic partners; whereas 
purpose in life and mastery will develop independently across time among youth with low levels of social support. Sex differences in the pathways between purpose in life and mastery will also be examined. Studies that have investigated sex differences in purpose in life and mastery have provided inconsistent findings (Damon et al., 2003). Therefore, we do not have specific hypotheses as to whether the pathways between purpose in life and mastery will differ for male and female participants.

\section{Method}

\section{Participants}

The current study used the final three waves of data from the Victoria Healthy Youth Survey (V-HYS) when participants were between 18 to 25 years of age at baseline (T1 Mage= 22.33, $S D=1.96)$. Participants were interviewed in 2009 ( $n=459 ; 44 \%$ male $), 2011$ ( $n=463$; $46 \%$ male), and 2013 ( $n=478 ; 45 \%$ male). The original sample of the V-HYS consisted of 662 (ages 12 to $18 ; 48.3 \%$ male) youth selected from a medium-sized urban community. The sample identified primarily as Caucasian $(85 \%)$ and $61 \%$ of fathers and $70 \%$ of mothers had at least some college or university training.

\section{Procedure}

The V-HYS data collection began in $2003(N=662 ; 48 \%$ male) and continued biennially until 2013 (see Leadbeater et al., 2012). Participants were obtained through a random sample of 9,500 telephone listings with 1,036 households identified eligible, housing an adolescent (ages 12 to 18). Of these households, 185 parents or guardians and 187 adolescents declined participation in the study. Retention rates over the course of the study were high (ranged from $70 \%$ to $87 \%$ ). For youth over age 18, youth provided informed written consent. A trained interviewer administered the V-HYS in the participant's home or another private location. Participants completed a self-report portion of the survey individually for items dealing with private topics (e.g., mental health indicators and substance use). This portion of the interview was selfadministered and placed in a sealed envelope not accessible to the interviewer. Gift certificates were awarded for participation at each interview.

\section{Measures}

\section{Purpose in Life}

The purpose in life subscale from Ryff's (1989) psychological well-being scale was used in the present study to assess purpose in life. The nine item subscale taps having a sense of direction in life, purpose and meaning, and objectives (e.g., "I enjoy making plans for the future and working 
to make them a reality;" "I am an active person in carrying out the plans I set for myself."). Youth responded with their level of agreement to these statements on a 6-point Likert scale ranging from (0) strongly agree to (6) strongly disagree. The items were summed to create a composite score that were used in the analyses. Internal consistencies were .80 at $\mathrm{T} 1, .78$ at $\mathrm{T} 2$, and .79 at $\mathrm{T} 3$, respectively.

\section{Mastery}

The environmental mastery subscale also from Ryff's (1989) psychological well-being scale, was used to assess mastery. The nine item subscale measures youth's sense of control over their environment and ability to make use of available opportunities (e.g., "In general, I feel I am in charge of the situation in which I live in;" "I am quite good at managing the many responsibilities of my daily life."). Youth indicated their level of agreement with each statement ranging from (0) strongly agree to (6) strongly disagree. The items were summed to create a composite score that were used in the analyses. Internal consistencies were adequate across waves; .78 at $\mathrm{T} 1, .79$ at $\mathrm{T} 2$, and .82 at $\mathrm{T} 3$.

\section{Father and Mother Emotional Support}

Schaefer's (1965) inventory of parental behaviors assessed father and mother emotional support. Participants rated on a 0 (not like him or her) to 2 (like him or her) scale how much they felt five statements were like their father and mother separately (e.g., "My father/mother is a person who understands my problems and worries"). Internal consistencies were adequate across waves for the father (.81 at T1,.81 at T2, and .82 at T3) and mother (.74 at each wave) scales.

\section{Friend Emotional Support}

Nine items from the Perceived Social Support measure (Procidano \& Heller, 1983) assessed whether or not participants received various forms of emotional support from their friends (e.g., "I rely on my friends for emotional support") on a scale of 0 (no), 1 (yes). Internal consistencies were .65, .66, and .57 for friend emotional support at T1, T2, and T3, respectively.

\section{Romantic Partner Emotional Support}

Youth who responded to questions about romantic partner emotional support were currently in a romantic relationship during that assessment period. At T1, 249 (46\%; 155 females) were in a relationship, 280 (61\%; 168 females) at T2, and 301 (65\%; females) at T3. The quality of participants' current romantic relationship was assessed with three items developed for the VHYS. Youth rated how true three statements were for them on a five-point scale $(0=$ not at all true 
to 4 = very true). Items were "I feel a strong bond with my partner," "My partner and I are really important to each other," and "I can rely on my partner." Internal consistencies were .83 at T1, .76 at $\mathrm{T} 2$, and .83 at $\mathrm{T} 3$, respectively.

\section{Plan for Analyses}

Latent growth analyses (Bollen \& Curran, 2006) were used describe trajectories of purpose in life and mastery across the transition to young adulthood. Next, autoregressive, cross-lagged path analyses were used to assess the directionality of links between purpose in life and mastery. We compared the fit of four models sequentially: 1) The baseline model included autoregressive paths and concurrent associations between purpose in life and mastery across the three waves to determine the stability of the two constructs; 2) Building on the baseline model, the purpose-driven model added paths from purpose in life to subsequent levels of mastery (i.e., purpose T1 to mastery $\mathrm{T} 2$; purpose $\mathrm{T} 2$ to mastery $\mathrm{T} 3$ ) to test the hypothesis that purpose in life is the primary motivator behind increases in mastery beyond stability in mastery and concurrent associations with purpose and mastery; 3) The mastery-driven model examines paths from mastery to subsequent levels of purpose in life (i.e., mastery T1 to purpose T2; mastery T2 to purpose T3) to test the hypothesis that having a sense of mastery is the primary motivator behind increases in purpose in life beyond stability in purpose and concurrent associations with mastery and purpose; and, 4) The transactional model examines bidirectional paths between purpose in life and mastery to test the hypothesis that purpose and mastery reciprocally influence one another over time. Each model controlled for the influence of sex, age at T1, and SES (assessed by mother's education level). Sex was also assessed as a grouping moderator variable to test if pathways between purpose in life and mastery differ by male and female participants. The models did not differ significantly by sex, thus sex was entered as a control variable in all subsequent models.

Mplus statistical software (Muthén \& Muthén, 1998-2012) version 7 was used to test the fit of the hypothesized models. Missing data was handled using full information maximum likelihood procedures. Following established guidelines (Byrne, 2010; Hu \& Bentler, 1995; Kline, 2005), model fit was evaluated using the comparative fit indices (CFI), root-mean square error of approximation (RMSEA), and standardized root-mean of the residual (SRMR) that are sensitive to model complexity. CFI values of $>.95$ represent an exceptional fitting model and $>.90$ indicate reasonable good fit; RMSEA and SRMR values >.05 suggest excellent model fit, and values between .05 and .08 indicate reasonable fit. The chi-square likelihood ratio difference test was used to assess whether each successive model differed from the previous, nested model (e.g., fit of purpose-driven model to the stability model).

To assess the moderating role of emotional support (from parents, friends, and romantic partners), high and low support groups were created by averaging participants' scores on each scale across all three waves, calculating the overall means of these scores, and splitting the groups into those above the mean (high group) and those below (low group). Multiple-group analyses were used to assess differences in fit related to the moderating effects of mother, father, friend, and romantic partner emotional support. Chi-square difference tests were used to compare the fit of the models with the cross-lagged estimates allowed to vary (unconstrained) by the moderator 
against the fit of the model the cross-lagged parameters fixed to be equal (constrained) across the support groups. A significant difference between the constrained and unconstrained models indicates that the model varies by group.

\section{Results}

\section{Development of Purpose and Mastery across the Transition}

Findings from the latent growth analyses show that, on average, purpose in life increased over time $\left(\beta_{\text {slope }}=.30, S E=.13, p=.02\right)$ and mastery was stable $\left(\beta_{\text {slope }}=.18, S E=.11, p=.12\right)$.

\section{Longitudinal Associations between Purpose and Mastery}

Results from the model comparisons are shown in Table 1. Figure 1 shows the standardized results of the paths estimated for each model. Within-time correlations between purpose and mastery were included in all models but are not shown in the figure for clarity $(r s=.68, .39$, and $.46, p \mathrm{~s}<.01$ for T1, T2 and T3 respectively). All three models (i.e., the purpose-driven, masterydriven, and transactional models) fit significantly better than the baseline model. The transactional model was a better fitting model than the mastery-driven model $\left(\Delta \chi^{2}(2)=25.11, p<.01\right)$, but was not significantly better than the purpose-driven model $\left(\Delta \chi^{2}(2)=5.28, p=.07\right)$. However, overall fit indices suggest that the transactional model best fit the data $(\mathrm{CFI}=.95, \mathrm{RMSEA}=.17, \mathrm{SRMR}$ $=.03$ ), suggesting that purpose and mastery influence one another over time (see Figure 1D).

\section{Moderating Effects of Emotional Support from Parents, Peers, and Romantic Partners}

Table 2 provides descriptive statistics for purpose in life and agency by high and low support groups. Youth who reported higher mean levels of emotional support (i.e., mother, father, friend, and romantic relationship) consistently reported higher levels of purpose in life and mastery at each time point with the exception of mastery at T1 for mother social support. The multiplegroup model for both mother and father emotional support were not significant $\left(\Delta \chi^{2}(8)=13.06\right.$, , $p<.001$ and $\Delta \chi^{2}(8)=7.99, p<.001$, respectively). The multiple-group models were significant for friend $\left(\Delta \chi^{2}(8)=15.73, p<.001\right)$ and romantic partner $\left(\Delta \chi^{2}(8)=22.37, p<.001\right)$ emotional support indicating that the path parameters presented in Figure 1D (transactional model) differed by group.

\section{Friend Emotional Support}

Among youth who had reported high levels of friend emotional support, mastery at T1 predicted higher levels of purpose at $\mathrm{T} 2, \beta=.24$, which subsequently predicted higher levels of 
mastery at T3, $\beta=.26$ (see Figure $2 \mathrm{~B}$ ). Purpose in life at T1 predicted higher levels of mastery at $\mathrm{T} 2, \beta=.16$ and subsequently predicted higher levels of purpose in life at T3, $\beta=.16$. In contrast, for youth who had low levels of friend emotional support only, mastery at T1 predicted higher levels of purpose at T2 only, $\beta=.27$.

\section{Romantic Partner Emotional Support}

Among youth who had high levels of romantic partner support, pathways from mastery to purpose (i.e., T1 to T2 and T2 to T3) were significant, $\beta \mathrm{s}=.26$ and .16 , respectively (see Figure $3 \mathrm{~B})$. In addition, purpose in life predicted higher levels of mastery from T2 to T3, $\beta=.22$. For youth who had low levels of romantic partner support, only mastery at T1 predicted higher levels of purpose at $\mathrm{T} 2, \beta=.37$.

\section{Discussion}

The current study examined the reciprocal associations between purpose in life and mastery across the transition to young adulthood in a sample of Canadian youth. On average, purpose in life increased over the six years of data collection, suggesting that youth continue to develop purpose as they enter young adulthood. Levels of mastery achieved by age 18, over average, did not change over time. A transactional model between purpose in life and mastery best fit the data demonstrating that both assets appear to predict and influence each other over time. Emotional support from friends and romantic partners but not parents, moderated the association between purpose in life and mastery. As hypothesized, purpose in life and mastery were reciprocally related in youth who had reported high levels friend and romantic partner support compared to youth who reported low levels of support. Further, consistent with the identity status literature (e.g., Côté, 2009), men and women did not differ in their associations between purpose in life and mastery.

\section{The Relation between Purpose in Life and Mastery}

Our findings show direct and reciprocal associations between purpose in life and mastery across six years spanning the transition to young adulthood. More specifically, mastery predicted purpose in life during early young adulthood (T1 to T2), and purpose in life and mastery were reciprocally related during young adulthood (T2 to T3). The transition to young adulthood offers opportunities to explore identity roles that lend to the co-occurring development of purpose in life and mastery. Youth are afforded new-found independence when they begin to live independently and enrol in post-secondary education or vocational training which enables them to practice selfgovernance and develop mastery (Zarrett \& Eccles, 2006). Youth may build on mastery established in adolescence to take advantage of a range of opportunities and manage new environments to adjust to their rapidly changing life circumstances. Mastery also may spur achievements in young adulthood that are the foundations of purpose in life. Colleges and universities also serve as social institutions that provide some youth with organized, civic activities (e.g., social, political, 
environmental activism), which can help inspire youths' sense of purpose (Flanagan \& Levine, 2010; Youniss \& Levine, 2009). Youth who commit to a purpose may work to master towards opportunities that are compatible with their goals and align with their perceived strengths, which, in turn, can further support their sense of mastery and competence (reflecting the reciprocal relation between purpose and agency in mid- to late- young adulthood).

\section{The Effects of Emotional Support on the Development of Purpose in Life and Agency}

The longitudinal associations between purpose in life and agency varied by levels of emotional support. Notably, youth with higher mean levels of emotional support across all sources (i.e., parent, peer, and romantic partner) reported higher levels of purpose in life and mastery consistently at each time point compared to youth who reported lower levels. Affirming social contexts are important for identity development as youth rely on their social networks to reinforce their sense of belonging and purpose and mastery (e.g., Hagerty et al., 2002; Jose et al., 2012; Schachter \& Ventura, 2008). As Erikson (1970) described, an individual's identity is "a subjective sense as well as an observable quality of personal sameness and continuity, paired with some belief in the sameness and continuity of some shared world image" (p. 20). External support for one's personal identity can enhance the congruency between an individual's purpose in life and available life choices. Conversely, a lack of support can threaten one's personal goals and may mitigate the sense of purpose and mastery within an individual.

Mother and father emotional support did not moderate pathways between purpose in life and mastery. In the transition to young adulthood, youth increasingly seek support from sources other than parents (i.e., friend and romantic partners). As youth begin to live independently from their parents, shed superficial relationships and strengthen meaningful ones (Carstensen, 1992), the quality of support from close friends and romantic partners may foster the co-development of purpose and mastery. It is also possible that low parental support in the form of psychological control can limit personal competence and hamper youth's efforts to develop purpose (Grolnick, 2002; Barber \& Harmon, 2002). However, the measure used to capture parent support in our study does not represent manipulative attempts to psychologically control youth through emotional and behavioural strategies. Research shows parental support is important for other outcomes (e.g., internalizing and externalizing problems, academic achievement and work outcomes; Desjardin \& Leadbeater, 2017; Yeung \& Leadbeater, 2013) that were not examined in this study.

Youth reporting high levels of peer support showed the same relations over time as the overall transactional model. Mastery at T1 only predicted purpose in life at T2 for youth with low levels of peer support. Youth with poorer quality of peer support may not experience the affirming relations that enable the co-development of purpose in life and mastery later in young adulthood and rely on their own mastery to spur purpose during young adulthood. Friendships during adolescence may be abundant, superficial, and transient in nature as youth begin to explore different friendships that fit with their identity roles within various contexts (Arnett, 2000). As youth progress into young adulthood and begin to adopt adult roles, they may start to select friendships that are more emotionally meaningful and shed ones that are not congruent with their purposes or identity. This is exemplified in studies that show that rates of interaction with 
acquaintances decline steadily from young adulthood but interactions in significant relationships increase (Carstensen, 1992; English \& Carstensen, 2014). The rewarding and enduring friendships that youth choose to invest in during later young adulthood appear to enhance youth's sense of purpose and provide support for their competence and mastery.

For youth reporting high levels of romantic partner support, relations between purpose in life and mastery were reciprocal only between T2 and T3. Youth with high and low levels of romantic partner support primarily relied on their sense of mastery to develop purpose in life between T1 and T2. Supportive romantic partners may play a larger role in helping youth develop purpose in life and agency later in young adulthood as youth begin to enter more long-term, committed, and intimate relationships (Brown, 1999; Collins, Welsh, \& Furman, 2009). As romantic relationships during young adulthood begin to involve shared values and belief systems (i.e., a relational identity; Brown, 1999), affirming romantic relationships could foster the codevelopment of purpose in life and mastery. Future research is needed to determine how these assets change as youth progress into adulthood.

\section{Limitations}

This study has limitations that could be addressed in future research. The measures used to tap support focused on emotional support, and other types of support (e.g., instrumental support from parents) may be important. The moderating effects of other types of support such as instrumental, appraisal, and informational supports (Malecki \& Demaray, 2003) on purpose in life and mastery need to be examined. A more detailed assessment, such as qualitative interviews, may also illuminate how youth use the emotional support they are receiving to inform their sense of purpose in life and support their mastery. Also limiting our findings, participants in this study are primarily Caucasian so findings are not generalizable to ethnic minority youth. Future research is needed to replicate these findings with a more diverse sample as aspects of identity may differ across ethnic or cultural groups (e.g., Schwartz et al., 2005).

\section{Conclusion}

Despite these limitations, the current study supports a growing body of literature focuses positive assets for youth development. In particular, our findings show that purpose in life and mastery influence each other across the transition to young adulthood. Further, we highlight the role that strong support systems can have on shaping the interaction between youth's purpose in life and mastery. Purpose in life and mastery have significant implications for positive youth development, psychosocial adjustment, and for the promotion of civic engagement (Flanagan \& Levine, 2010; Hardy et al., 2014). Healthy parent, peer, and romantic partner communication is critical during the transition to young adulthood when youth are faced with important decisions about education, career, and interpersonal relationships which can have long-term implications for their purpose in life and experiences of mastery in managing opportunities available to them. 


\section{References}

Adams, G. R., \& Marshall, S. K. (1996). A developmental social psychology of identity: Understanding the person-in-context. Journal of Adolescence, 19(5), 429-442.

Adler, J. M. (2012). Living into the story: Agency and coherence in a longitudinal study of narrative identity development and mental health over the course of psychotherapy. Journal of Personality and Social Psychology, 102(2), 367-389. doi:10.1037/a0025289

Barber, B. K., \& Harmon, E. L. (2002). Violating the self: Parental psychological control of children and adolescents. In Barber, B. K. (ed.), Intrusive Parenting: How Psychological Control Affects Children and Adolescents. APA, Washington, DC, pp. 15-52.

Bollen, K.A., \& Curran, P.J. (2006). Latent curve models: A structural equation approach. Hoboken, NJ: Wiley.

Brassai, L., Piko, B. F., \& Steger, M. F. (2011). Meaning in life: Is it a protective factor for adolescents' psychological health? International Journal of Behavioral Medicine, 18(1), 44-51.

Brauer, J. R. (2017). Cultivating conformists or raising rebels? Connecting parental control and autonomy support to adolescent delinquency. Journal of Research On Adolescence, 27(2), 452-470. doi:10.1111/jora.12283

Brown, B.B. (1999). "You're going out with who?': Peer group influences on adolescent romantic relationships. In W. Furman, B.B. Brown, \& C. Feiring (Eds.), The Development of Romantic Relationships in Adolescence (pp. 291-329). Cambridge: Cambridge University Press

Bundick, M. J., \& Tirri, K. (2014). Student perceptions of teacher support and competencies for fostering youth purpose and positive youth development: Perspectives from two countries. Applied Developmental Science, 18(3), 148-162.

Burrow, A. L., O’Dell, A. C., \& Hill, P. L. (2010). Profiles of a developmental asset: Youth purpose as a context for hope and well-being. Journal of Youth and Adolescence, 39, 1265-1273. doi:10.1007/ s10964-009-9481-1

Burrow, A. L., \& Hill, P. L. (2011). Purpose as a form of identity capital for positive youth adjustment. Developmental Psychology, 47(4), 1196. doi: 10.1037/a0023818

Byrne, B. M. (2010). Structural equation modeling with AMOS: Basic concepts, applications, and programming (2nd ed.). Mahwah, NJ: Lawrence Erlbaum Associates.

Carstensen, L. L. (1992). Social and emotional patterns in adulthood: Support for socioemotional selectivity theory. Psychology and Aging, 7(3), 331-338. doi:10.1037/0882-7974.7.3.331

Colarossi, L. G., \& Eccles, J. S. (2003). Differential effects of support providers on adolescents' mental health. Social Work Research, 27, 19-30.

Colman, I., Zeng, Y., McMartin, S. E., Naicker, K., Ataullahjan, A., Weeks, M., ... Galambos, N. L. (2014). Protective factors against depression during the transition from adolescence to adulthood: Findings from a national Canadian cohort. Preventive Medicine, 65, 28-32. doi:10.1016/j.ypmed.2014.04.008

Côté, J. E. (2009). Identity Formation and Self-Development in Adolescence. Handbook of adolescent psychology. 
Côté, J. E., \& Levine, C. G. (2014). Identity, formation, agency, and culture: A social psychological synthesis. Psychology Press.

Côté, J. E., \& Schwartz, S. J. (2002). Comparing psychological and sociological approaches to identity: Identity status, identity capital, and the individualization process. Journal of Adolescence, 25(6), 571-586. doi:10.1006/jado.2002.0511

Côté, J., \& Bynner, J. M. (2008). Changes in the transition to adulthood in the UK and Canada: The role of structure and agency in emerging adulthood. Journal of Youth Studies, 11(3), 251-268. doi:10.1080/13676260801946464

Cotton Bronk, K., Hill, P. L., Lapsley, D. K., Talib, T. L., \& Finch, H. (2009). Purpose, hope, and life satisfaction in three age groups. The Journal of Positive Psychology, 4(6), 500510.

Deci, E. L., \& Ryan, R. M. (2012). Motivation, personality, and development within embedded social contexts: An overview of self-determination theory. In R. M. Ryan (Ed.), The Oxford Handbook of Human Motivation (pp. 85-107). New York, NY: Oxford University Press.

Desjardins, T., \& Leadbeater, B. J. (2017). Changes in Parental Emotional Support and Psychological Control in Early Adulthood: Direct and Indirect Associations With Educational and Occupational Adjustment. Emerging Adulthood, 5(3), 177-190.

Emirbayer, M., \& Mische, A. (2013). What is agency? American Journal of Sociology, 103(4), 962-1023. doi:10.1086/231294

English, T., \& Carstensen, L. L. (2014). Selective narrowing of social networks across adulthood is associated with improved emotional experience in daily life. International Journal of Behavioral Development, 38(2), 195-202. DOI: 10.1177/0165025413515404

Erikson, E. (1968). Youth: Identity and crisis. New York, NY: Norton.

Erikson, E. (1970), 'Reflections on the dissent of contemporary youth', International Journal of Psychoanalysis, 51, pp. 11-22.

Flanagan, C., \& Levine, P. (2010). Civic engagement and the transition to adulthood. The future of Children, 20(1), 159-179.

Frankl, V. (1959). Man's search for meaning. New York: Washington Square Press.

Garcia, D., \& Siddiqui, A. (2009). Adolescents' psychological well-being and memory for life events: influences on life satisfaction with respect to temperamental dispositions. Journal of Happiness Studies, 10(4), 407-419.

Grolnick, W. S. (2002). The Psychology of Parental Control: How Well-Meant Parenting Backfires. Erlbaum, Mahwah, NJ.

Hardy, S. A., Walker, L. J., Olsen, J. A., Woodbury, R. D., \& Hickman, J. R. (2014). Moral identity as moral ideal self: Links to adolescent outcomes. Developmental Psychology, 50(1), 45-57.

Hagerty, B. M., Williams, R. A., \& Oe, H. (2002). Childhood antecedents of adult sense of belonging. Journal of Clinical Psychology, 58(7), 793-801.

Henry, K. L., Lovegrove, P. J., Steger, M. F., Chen, P. Y., Cigularov, K. P., \& Tomazic, R. G. (2014). The potential role of meaning in life in the relationship between bullying victimization and suicidal ideation. Journal of Youth and Adolescence, 43(2), 221-232.

Hill, P. L., Burrow, A. L., \& Sumner, R. (2013). Addressing important questions in the field of adolescent purpose. Child Development Perspectives, 7(4), 232-236. 
Hitlin, S., Erickson, L. D., \& Brown, J. S. (2015). Agency and mental health: A transition to adulthood paradox. Society and Mental Health, 1-19. doi:10.1177/2156869315573632

Hu, L., \& Bentler, P. M. (1995). Evaluating model fit. In R. H. Hoyle (Ed.), Structural equation modeling: Concepts, issues, and applications (pp. 76-99). Thousand Oaks, CA: Sage.

Jose, P. E., Ryan, N., \& Pryor, J. (2012). Does Social Connectedness Promote a Greater Sense of Well-Being in Adolescence Over Time? Journal of Research on Adolescence, 22(2), 235251.

Kiang, L. (2012). Deriving daily purpose through daily events and role fulfillment among Asian American youth. Journal of Research on Adolescence, 22(1), 185-198. doi: 10.1111/j.1532-7795.2011.00767.x

Kiang, L., Andrews, K., Stein, G. L., Supple, A. J., \& Gonzalez, L. M. (2013). Socioeconomic stress and academic adjustment among Asian American adolescents: The protective role of family obligation. Journal of Youth and Adolescence, 42(6), 837-847. doi: 10.1007/s10964-013-9916-6

Kiecolt, K. J., \& Mabry, J. B. (2000). Agency in young adulthood: Intentional self-change among college students. Advances in Life Course Research, 5, 181-205. doi:10.1016/S1040-2608(00)80012-X

Kline, R. B. (2005). Principles and practice of structural equation modeling (2nd ed.). New York, NY: Guilford Press.

Lambert, N. M., Stillman, T. F., Hicks, J. A., Kamble, S., Baumeister, R. F., \& Fincham, F. D. (2013). To belong is to matter sense of belonging enhances meaning in life. Personality and Social Psychology Bulletin, 39(11), 1418-1427. doi: 10.1177/0146167213499186

Leadbeater, B., Thompson, K., \& Gruppuso, V. (2012). Co-occurring trajectories of symptoms of anxiety, depression, and oppositional defiance from adolescence to young adulthood. Journal of Clinical Child \& Adolescent Psychology, 41(6), 719-730. DOI:10.1080/15374416.2012.694608

Lerner, R. M. (2017). Commentary: Studying and Testing the Positive Youth Development Model: A Tale of Two Approaches. Child Development. 88(4), 1183-1185

Lerner, R. M., Dowling, E. M., \& Anderson, P. M. (2003). Positive youth development: Thriving as the basis of personhood and civil society. Applied Developmental Science, 7(3), 172180.

Malecki, C. K., \& Demaray, M. K. (2003). What type of support do they need? Investigating student adjustment as related to emotional, informational, appraisal, and instrumental support. Social Psychology Quarterly, 18, 231-252

Marcia, J. E. (1980). Identity in adolescence. Handbook of adolescent psychology, 9, 159-187.

Meeus, W. I. M., Oosterwegel, A., \& Vollebergh, W. (2002). Parental and peer attachment and identity development in adolescence. Journal of Adolescence, 25(1), 93-106. doi:10.1006/jado.2001.0451

Minehan, J. A., Newcomb, M. D., \& Galaif, E. R. (2000). Predictors of adolescent drug use: Cognitive abilities, coping strategies, and purpose in life. Journal of Child \& Adolescent Substance Abuse, 10(2), 33-52. doi: 10.1300/J029v10n02_04

Muthén, L.K. \& Muthén, B.O. (1998-2012). Mplus User's Guide. Seventh Edition. Los Angeles, CA: Muthén \& Muthén. 
Pizzolato, J. E., Brown, E. L., \& Kanny, M. A. (2011). Purpose plus: Supporting youth purpose, control, and academic achievement. New Directions for Youth Development, 2011(132), 75-88. doi: 10.1002/yd.429

Procidano, M. E., \& Heller, K. (1983). Measures of perceived social support from friends and from family: Three validation studies. American Journal of Community Psychology, 11(1), 1-24.

Ryff, C. D. (1989). Happiness is everything, or is it? Explorations on the meaning of psychological well-being. Journal of Personality and Social Psychology, 57(6), 10691081.

Ryff, C. D., \& Keyes, C. L. M. (1995). The structure of psychological well-being revisited. Journal of Personality and Social Psychology, 69(4), 719-727. doi: 10.1037/00223514.69.4.719

Schachter, E. P. and Ventura, J. J. (2008), Identity Agents: Parents as Active and Reflective Participants in Their Children's Identity Formation. Journal of Research on Adolescence, 18: 449-476. doi: 10.1111/j.1532-7795.2008.00567.x

Schaefer, E. (1965). Children's reports of parental behavior: An inventory. Child Development, 36(2), 413-424.

Schwartz, S. J., Côté, J. E., \& Arnett, J. J. (2005). Identity and agency in emerging adulthood: Two developmental routes in the individualization process. Youth \& Society, 37(2), 201229. doi: $10.1177 / 0044118 X 05275965$

Smetana, J. G., Metzger, A., Gettman, D. C., \& Campione-Barr, N. (2006). Disclosure and secrecy in adolescent-parent relationships. Child Development, 77, 201-217.

Soenens, B., \& Vansteenkiste, M. (2005). Antecedents and outcomes of self-determination in 3 life domains: The role of parents' and teachers' autonomy support. Journal of Youth and Adolescence, 34(6), 589-604. DOI: 10.1007/s10964-005-8948-y

Statistics Canada. (2012). Living arrangements of young adults aged 20 to 29: Families, households and marital status, 2011 census of population. Ottawa, Ontario: Ministry of Industry.

Steger, M. F., Bundick, M. J., \& Yeager, D. (2012). Meaning in life. In R. J. R Levesque (Ed.), Encyclopedia of Adolescence (pp. 1666-1677). United States: Springer.

Youniss, J., \& Levine, P. (Eds.). (2009). Engaging young people in civic life. Nashville, TN: Vanderbilt University Press.

Yeung Thompson, R. S., \& Leadbeater, B. J. (2013). Peer victimization and internalizing symptoms from adolescence into young adulthood: Building strength through emotional support. Journal of Research on Adolescence, 23(2), 290-303.

Zarrett, N., \& Eccles, J. (2006). The passage to adulthood: Challenges of late adolescence. New Directions for Youth Development, 111, 13-28. DOI: 10.1002/yd.179 
Table 1.

Comparisons of Path Models Testing Longitudinal Associations between Purpose and Mastery

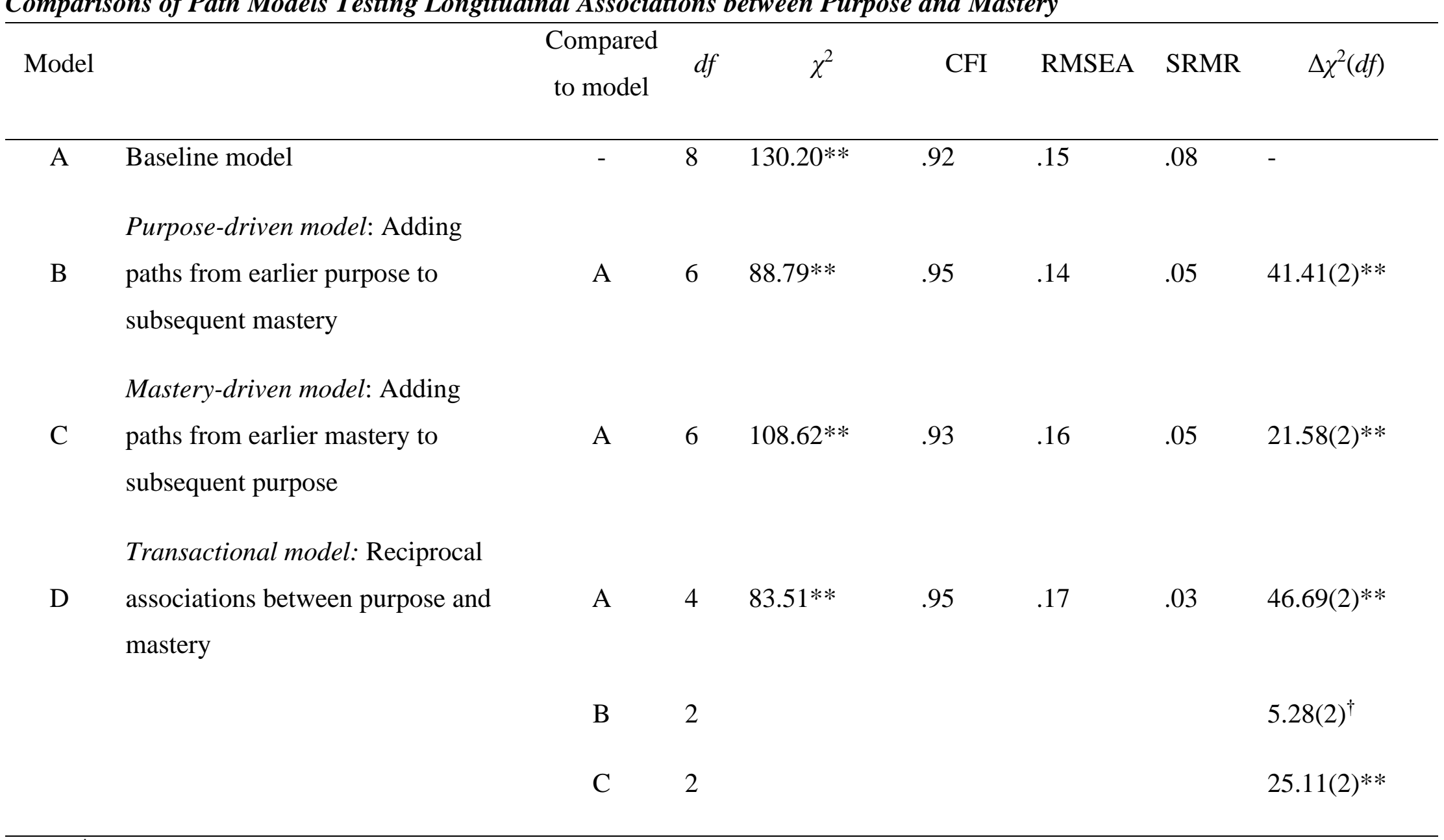

Note: ${ }^{\dagger} p=.18, * p<.05, * * p<.01$ 
Table 2.

Means (SD) for Purpose and Agency by high and low support groups and time in study.

\begin{tabular}{|c|c|c|c|c|c|c|c|c|}
\hline & \multicolumn{2}{|c|}{ Mother Support } & \multicolumn{2}{|c|}{ Father Support } & \multicolumn{2}{|c|}{ Friend Support } & \multicolumn{2}{|c|}{$\underline{\text { Romantic Partner Support }}$} \\
\hline & $\begin{array}{c}\text { High } \\
(n=369)\end{array}$ & $\begin{array}{c}\text { Low } \\
(n=170)\end{array}$ & $\begin{array}{c}\text { High } \\
(n=301)\end{array}$ & $\begin{array}{c}\text { Low } \\
(n=228)\end{array}$ & $\begin{array}{c}\text { High } \\
(n=340)\end{array}$ & $\begin{array}{c}\text { Low } \\
(n=206)\end{array}$ & $\begin{array}{c}\text { High } \\
(n=191)\end{array}$ & $\begin{array}{c}\text { Low } \\
(n=260)\end{array}$ \\
\hline \multicolumn{9}{|l|}{ Time 1} \\
\hline Purpose & $34.93(6.37)$ & $35.30(6.13)$ & $34.78(6.37)$ & $32.67(7.04)$ & $34.96(6.28)$ & $32.04(7.04)$ & $35.65(5.67)$ & $32.44(6.27)$ \\
\hline Mastery & $31.70(6.19)$ & $32.26(6.49)$ & $31.57(6.32)$ & $29.80(6.79)$ & $32.06(6.06)$ & $28.44(6.85)$ & $31.85(6.06)$ & $29.74(6.67)$ \\
\hline \multicolumn{9}{|l|}{ Time 2} \\
\hline Purpose & $34.45(6.27)$ & $31.516 .38)$ & $34.23(6.49)$ & $32.84(6.23)$ & $34.77(6.23)$ & $31.68(6.31)$ & $35.44(5.79)$ & $32.03(6.20)$ \\
\hline Mastery & $31.62(6.34)$ & $28.88(6.74)$ & $31.81(6.02)$ & $29.62(6.98)$ & $32.09(6.11)$ & $28.66(6.74)$ & $32.28(6.28)$ & $29.21(6.27)$ \\
\hline \multicolumn{9}{|l|}{ Time 3} \\
\hline Purpose & $35.30(6.13)$ & $32.20(6.56)$ & $34.89(6.62)$ & $33.49(6.08)$ & $35.22(6.29)$ & $32.86(6.32)$ & $36.04(5.61)$ & $33.07(6.11)$ \\
\hline Mastery & $32.26(6.49)$ & $28.88(7.57)$ & $32.01(7.07)$ & $30.21(6.97)$ & $32.58(6.45)$ & $29.00(7.39)$ & $32.73(6.75)$ & $29.64(6.59)$ \\
\hline
\end{tabular}

Note. All means are significantly different between the high and low groups $(p \mathrm{~s}<.01)$. 
A.

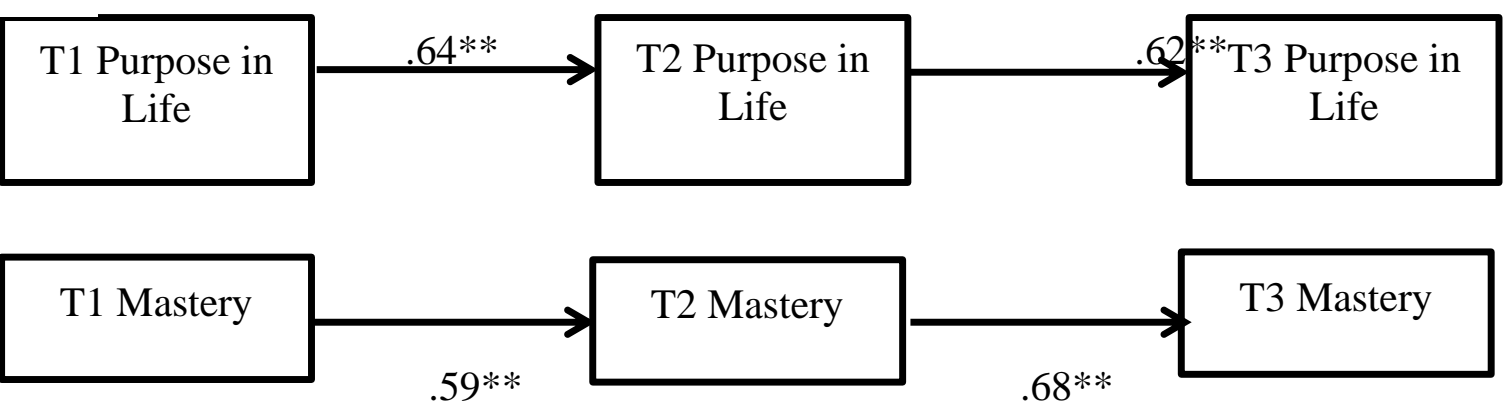

B.

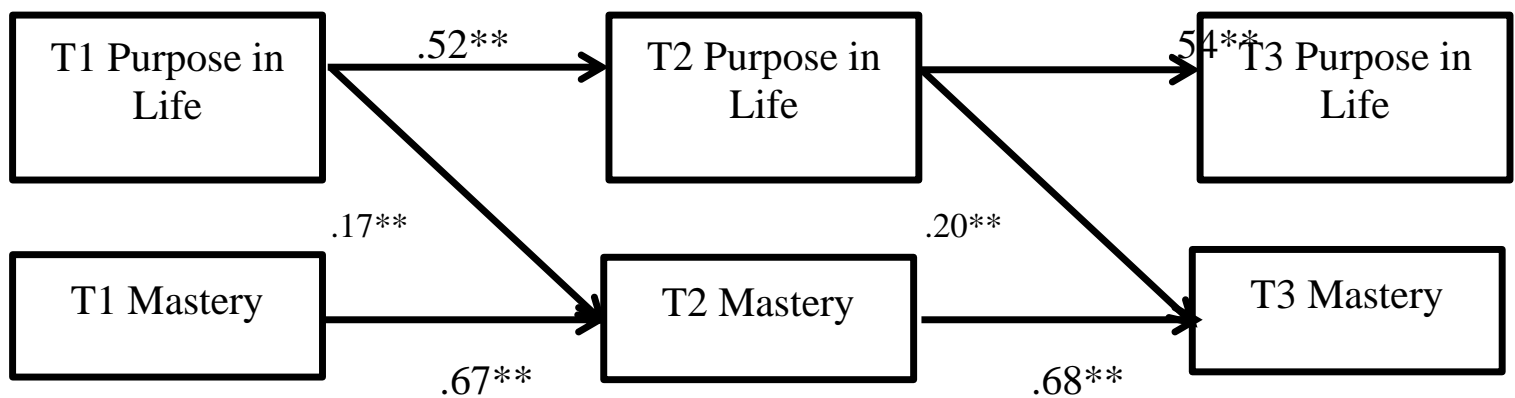

C.

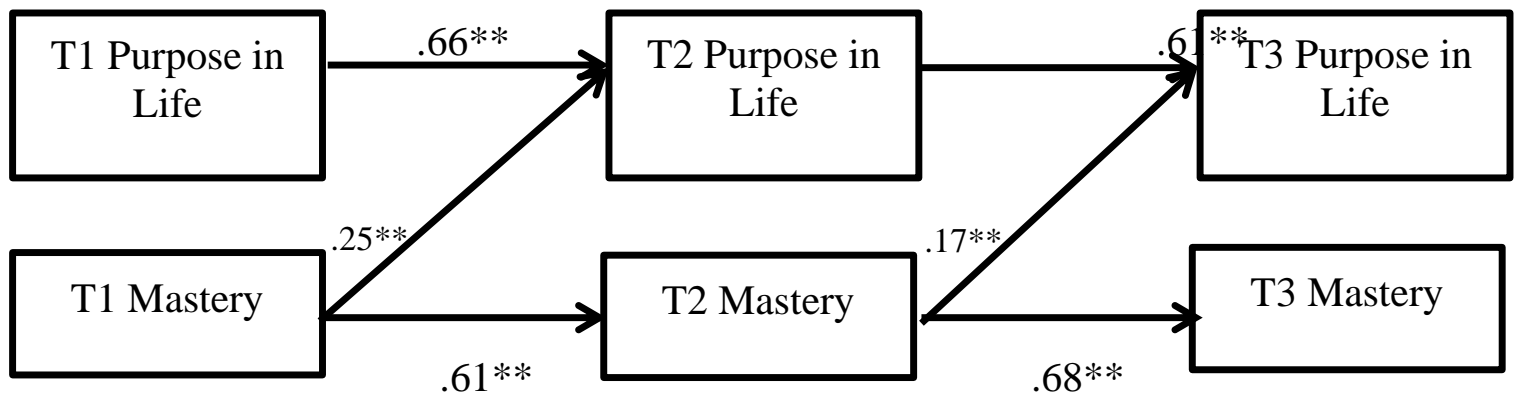

D.

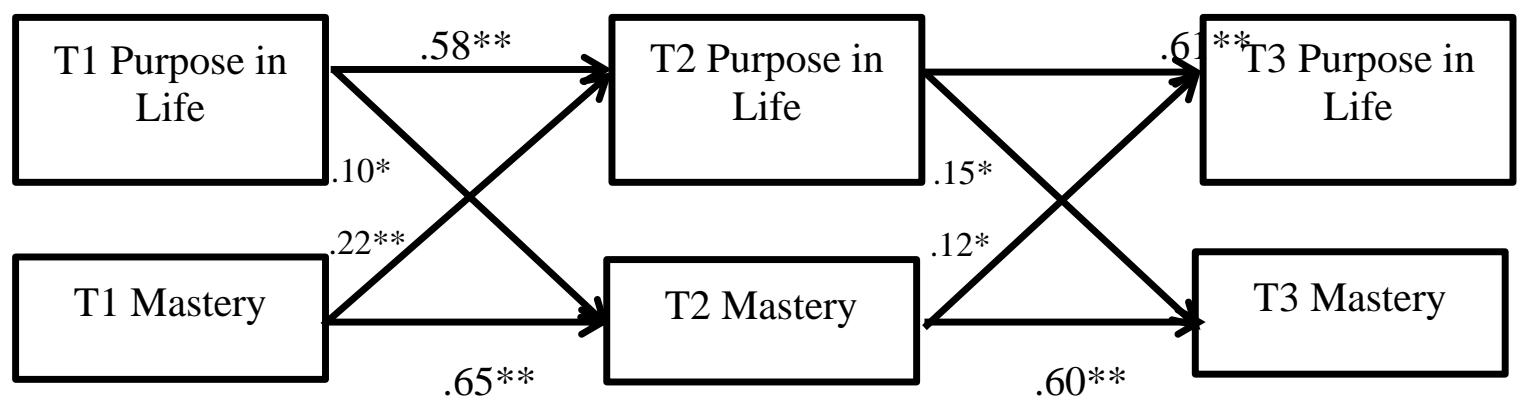

Figure 1. Autoregressive, cross-lagged path analyses assessing the (A) Baseline stability model; (B) Purpose-driven model; (C) Mastery-driven model; and (D)Transactional model: Bidirectional associations between purpose in life and mastery. All models controlled for age, gender, and SES. Standardized coefficients are presented. Within-time correlations are significant and positive but are not presented. $* p<.05, * * p<.001$ 


\section{A.) Low Friend Emotional Support}

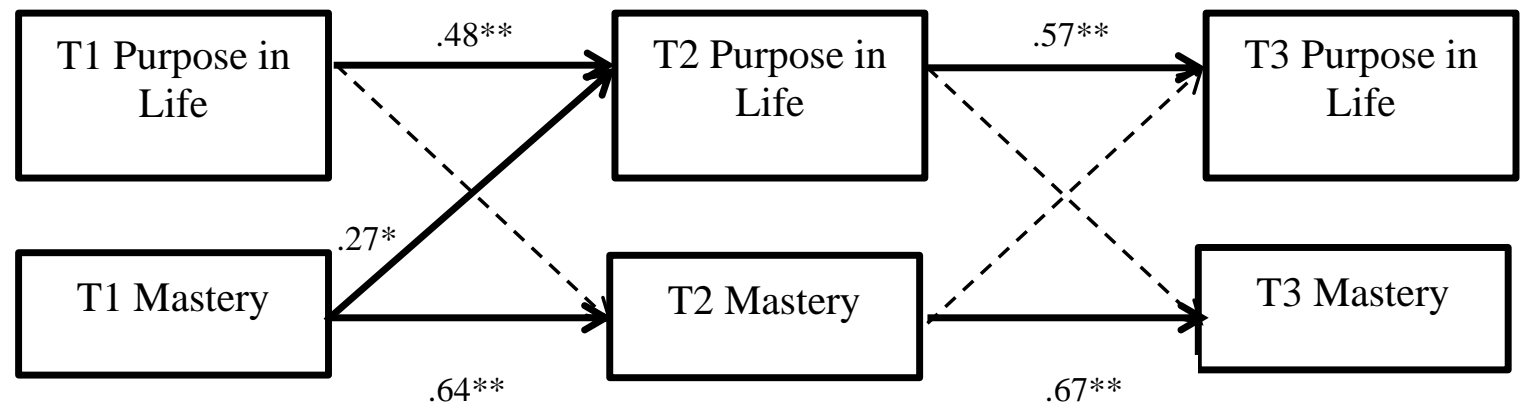

B.) High Friend Emotional Support

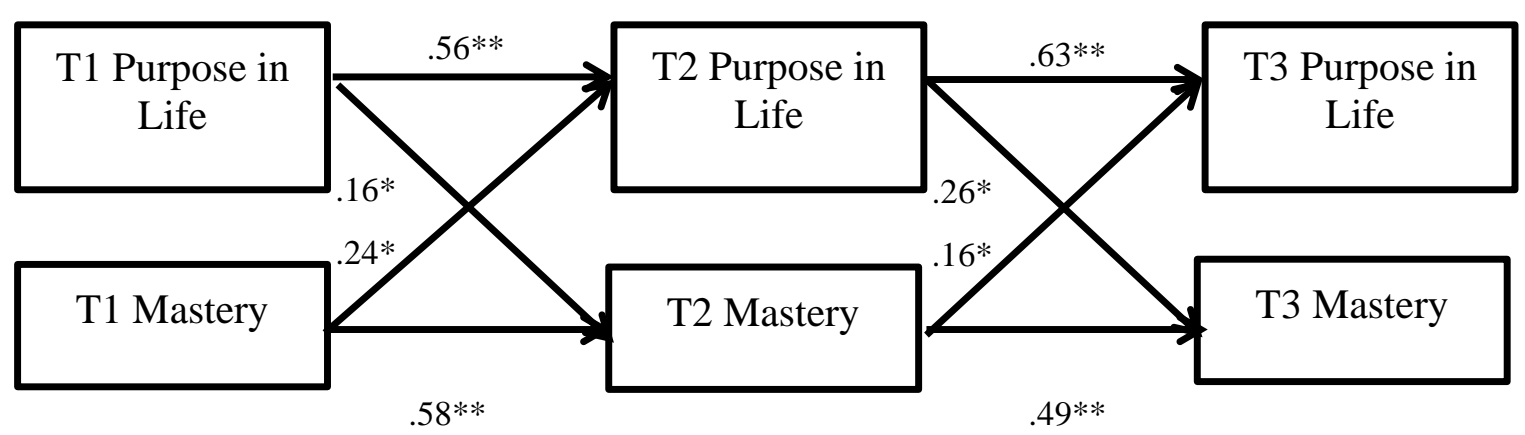

Figure 2. Bidirectional associations between purpose in life and mastery controlling for age, gender, and SES for youth with A.) low friend emotional support and B.) high friend emotional support. Standardized coefficients are presented. Dashed lines represent non-significant pathways. Within-time correlations are significant and positive but are not presented. ${ }^{*} p<.05$, $* * p<.001$ 


\section{Low Romantic Partner Emotional Support}

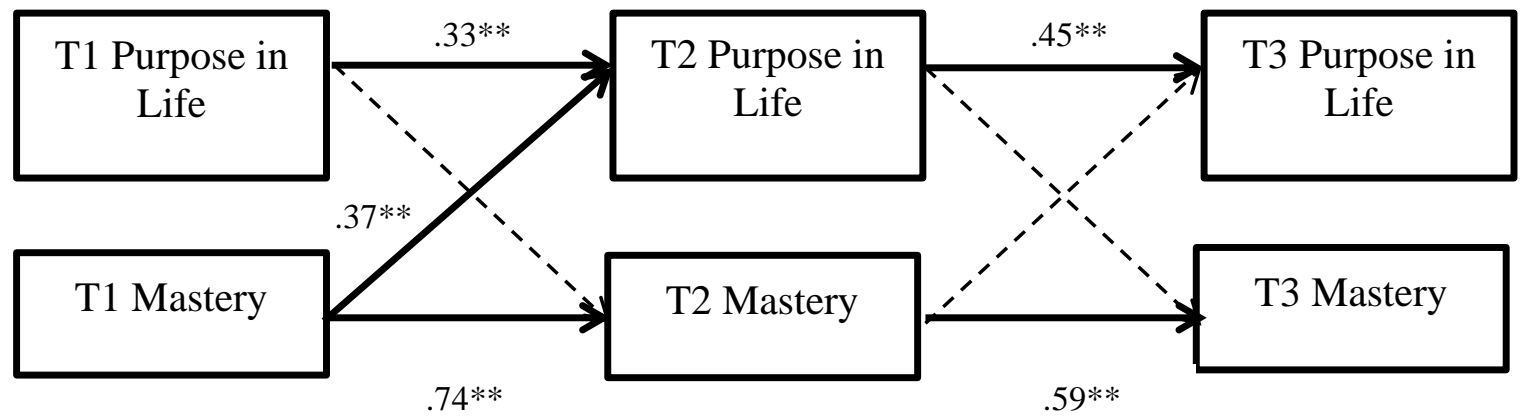

\section{A.) High Romantic Partner Emotional Support}

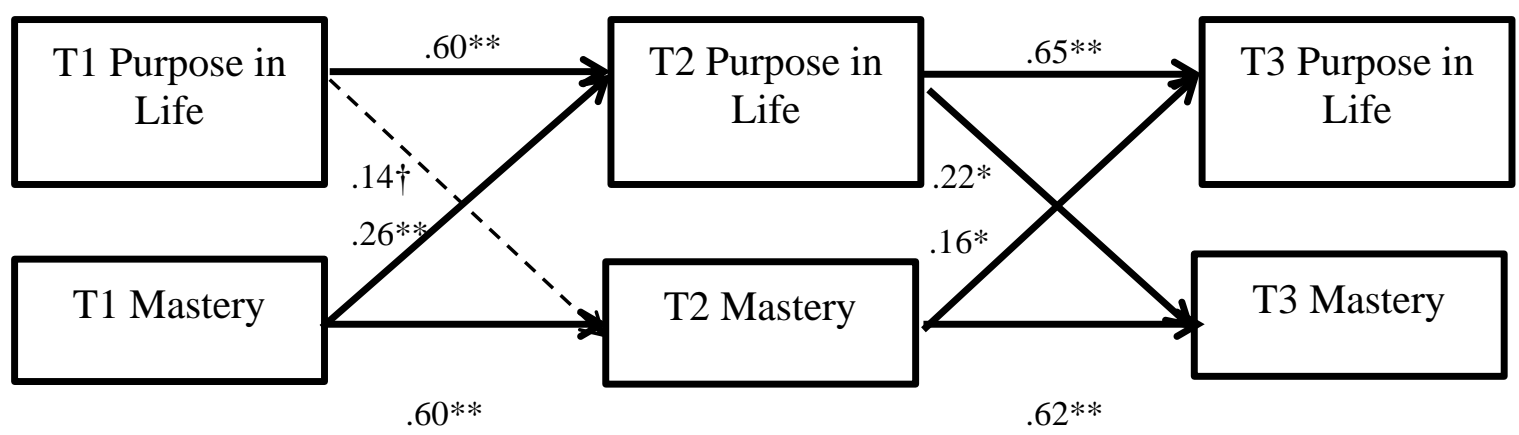

Figure 3. Bidirectional associations between purpose in life and mastery controlling for age, gender, and SES for youth with A.) low romantic partner emotional support and B.) high romantic partner emotional support. Standardized coefficients are presented. Dashed lines represent non-significant pathways. Within-time correlations are significant and positive but are not presented. $\dagger \mathrm{p}=.09 ; * p<.05, * * p<.001$ 